\title{
LEITURA E TECNOLOGIA: FORMANDO LEITORES EM UMA ESCOLA RURAL
}

\author{
Maire Josiane Fontana \\ Instituto Federal de Educação, Ciência e Tecnologia do Rio Grande do Sul
}

Resumo: Este estudo, pesquisa social de base empírica, consiste em uma análise participativa sobre a dimensão do desenvolvimento de práticas de leitura na formação leitora dos alunos do $8^{\circ}$ e $9^{\circ}$ anos da Escola Municipal Ensino Fundamental Francisco Rodrigues dos Santos, uma escola rural do município de Água Santa/RS, com ênfase nas representações construídas pelos estudantes. A escola em questão, mesmo com acesso à internet, não possibilita que os alunos usufruam dela. Para este estudo, desenvolveu-se uma pesquisa de cunho bibliográfico com base nos pressupostos teóricos de Judith Langer sobre a construção de representações e de Michèle Petit sobre a importância da leitura para a formação humana e para a inclusão social e, posteriormente, uma pesquisa-ação, que envolveu, inicialmente, a aplicação de um questionário aos alunos com questões relacionadas à leitura. Com base nas respostas, foi possível traçar um perfil leitor dos sujeitos participantes desta pesquisa. Em seguida, foram distribuídos livros literários aos alunos, de acordo com seus gostos literários e, após a leitura, foram desenvolvidas quatro práticas leitoras na escola, envolvendo a leitura e a escrita. Esta ação permitiu o contato dos participantes da pesquisa com leituras inovadoras e diferenciadas, abrindo caminhos para a formação de leitores literários inclusive em suporte digital, sempre no intuito de motivá-los para a leitura e de evidenciar a importância do professor como referência na formação e na mediação leitora. O trabalho, assim, dedicou um olhar aprofundado à leitura como prática social e literária associada às manifestações artísticoculturais em diferentes mídias.

Palavras-chave: Formação do leitor. Leitura. Mediação de leitura. Tecnologia.

\section{Introdução}

A leitura tem grande importância na vida do ser humano. Por meio dela, nos tornamos mais críticos, entendemos melhor o mundo em que vivemos, podemos viajar para lugares distantes sem sair do lugar, entre outros benefícios que só são possíveis a partir do contato com as letras. Mas o que se percebe é que a leitura, para um grande número de pessoas, não se configura como um hábito, nem como fonte de prazer, mas como uma tarefa obrigatória.

EY No NO Esta obra está licenciada sob uma Licença Creative Commons.

\footnotetext{
* Mestre em Letras pela Universidade de Passo Fundo (2013); Graduada em Letras/Espanhol e respectivas Literaturas (UPF - 2010); Especialista em Ensino e Aprendizagem de Língua Espanhola (UPF - 2011). Professora de Língua Portuguesa e Língua Espanhola no IFRS - Câmpus Sertão
} 
A leitura, principalmente a literária, que deveria ser iniciada desde muito cedo na vida das pessoas, estimulada pela família, é vista atualmente como uma incumbência da escola, a qual, muitas vezes, não desempenha seu papel da maneira como deveria. Utilizando a literatura apenas para mera decodificação, ou ainda para o trabalho gramatical, a escola acaba distorcendo o papel literário, eliminando seu potencial de encantamento e não cumprindo sua tarefa de formar leitores. Inúmeras vezes, inclusive, a leitura literária se dá tendo como suporte apenas o livro didático, que apresenta fragmentos de obras, não sendo possível entender o sentido verdadeiro e completo da obra literária. Ocorre, ainda, e com frequência, a leitura de textos desvinculados da realidade discente, o que torna ainda mais desmotivador o ato de ler, já que o aluno não se identifica com aquilo que a obra relata.

Diante dessa realidade preocupante que se apresenta em relação à leitura, entende-se que ações devem ser desenvolvidas para garantir a formação de leitores críticos, capazes de compreender e interpretar linguagens veiculadas em diferentes suportes.

Este estudo implica a observação do grau de importância e do impacto do desenvolvimento de práticas leitoras para duas turmas de alunos, $8^{\circ}$ e $9^{\circ}$ anos, da Escola Municipal Ensino Fundamental Francisco Rodrigues dos Santos, da cidade de Água Santa/RS, ambiente desprovido de materiais de leitura ${ }^{1}$ adequados e de recursos multimidiais. Busca-se, ainda, averiguar a significância dessas práticas na vida desses sujeitos e o que elas representam na sua história, bem como averiguar a importância das ações dos mediadores de leitura nesse contexto.

A justificativa para a realização deste estudo reside no fato de que a escola em questão é desprovida de materiais de leitura adequados e de recursos multimidiais, o que ocasiona a desmotivação dos alunos participantes da pesquisa para a leitura literária. Então, esta pesquisa pode vir a contribuir para o reconhecimento, cada vez maior, da realização das atividades leitoras literárias como iniciativa imprescindível e inovadora no que se refere ao fomento da leitura e à formação de leitores.

Para o desenvolvimento desta pesquisa, foi realizado um estudo do tipo pesquisaação, a partir de uma inferência embasada em um processo de mediação de leitura e práticas leitoras levadas a efeito com os alunos envolvidos. Vale salientar que se optou pela pesquisaação porque a pesquisa partiu da necessidade de uma ação que proporcione aos sujeitos envolvidos o contato com leituras diversificadas e em suportes diferenciados, de modo que

\footnotetext{
${ }^{1}$ Os materiais de leitura citados neste estudo referem-se a livros (literários ou não).
} 
possam ter maior acesso a textos e obras literárias, investigando, durante o tempo da pesquisa, o grau de eficiência da pesquisa-ação.

\section{Leitura e experiência literária}

$\mathrm{O}$ ato de ler é, sem dúvida, imprescindível no mundo moderno, pois insere os indivíduos na sociedade e os caracteriza como cidadãos participantes. A leitura é o eixo central no desenvolvimento do ser humano, pois com sua prática é possível adquirir novos conhecimentos e obter uma percepção do mundo que nos rodeia.

A literatura, desde que nascemos, é um meio essencial de comunicação conosco mesmos e com os outros. É também uma maneira de refletir sobre nossa própria vida, nossas opções, sobre a humanidade e o mundo em que vivemos.

De acordo com Langer:

Por meio da literatura os alunos aprendem a explorar possibilidades e a refletir sobre variadas opções para eles mesmos e para a humanidade. Por meio da literatura, eles encontram a si mesmos, imaginam como as outras pessoas são, valorizam a diferença e buscam justiça; ganham a capacidade de estabelecer analogias e buscam uma melhor compreensão do futuro. Eles se tornam o tipo de pensadores literatos dos quais necessitamos para dar forma às decisões que moldam o futuro (LANGER, 2005, p. 11).

Diante do exposto, percebe-se claramente que a literatura é fundamental para que o ser humano entenda a si mesmo e aos outros, para que definamos e redefinamos quem somos, quem podemos nos tornar e como o mundo é e pode vir a ser. A literatura desempenha papel fundamental em nossas vidas, mesmo que muitas vezes não nos demos conta. Por meio dela, é possível que utilizemos vários pontos de vista para a realização de uma análise de pensamentos, crenças e ações. "Vivenciar uma experiência literária envolve explorar nossa consciência sobre as coisas o máximo possível, enquanto mantemos uma abertura para possibilidades futuras" (LANGER, 2005, p. 7).

A escola possui papel fundamental no processo de formação de leitores. Se nela existem professores comprometidos com a tarefa de formar leitores, eles certamente encontrarão nos materiais literários meios para realizar seus objetivos.

Ao ler um texto literário, conceitos vão sendo criados para representar aquilo que lemos. Segundo Langer (2005), quando formamos um conceito de algo em certo momento, estamos fazendo representações, as quais são um produto de nossas experiências. A autora define melhor as representações, afirmando que

[...] são conjuntos dinâmicos de ideias, imagens, questionamentos, discordâncias, previsões, argumentações e intuições, relacionados, que preenchem a mente durante 
a leitura, a escrita, a fala, ou outra experiência em que esteja envolvida a aquisição, explicitação ou troca de pensamentos e conceitualizações (LANGER, 2005, p. 2223).

Contudo, é necessário destacar que uma representação está sempre sujeita a mudanças, sempre que há o surgimento de novas ideias. Por exemplo, durante uma leitura, à medida que ela avança, algumas ideias deixam de ser tão relevantes, outras são acrescentadas, e algumas são até reinterpretadas. Mesmo depois de terminada a leitura, as representações ainda podem se modificar, por meio de um debate em sala de aula, da escrita, de outras leituras etc. Elas "se desenvolvem, mudam e se enriquecem com o tempo, com o pensamento e com a experiência" (LANGER, 2005, p. 24). Todavia, as representações não acontecem apenas na literatura, mas também quando damos sentido a nós mesmos, aos outros e ao mundo.

Essa noção de representação nos permite entender que, após uma leitura, tanto os alunos como o professor possuem suas próprias representações iniciais sobre aquilo que leram, as quais estão sujeitas a mudança, devido às ideias dos colegas, do professor ou de suas próprias ideias. A compreensão momentânea e a compreensão do todo, portanto, estão constantemente abertas a modificações.

Assim, as representações dos alunos têm a ver com suas experiências de vida, bem como com seus objetivos de leitura, por aquilo que entendem em relação ao que o professor deseja e por sua percepção daquilo que consideram correto. Cada construção de representação é diferente, seja para pessoas diferentes numa mesma situação, para a mesma pessoa em situações diferentes, ou ainda para uma mesma pessoa numa mesma situação num momento futuro. Mas não se deve esquecer que, mesmo que os leitores apontem significados diferentes para o que o texto diz, o texto (e o autor que está por trás) influencia na nossa leitura. E a escola tem um papel decisivo no processo de formação de leitores, de construção de representações, e de proporcionar o encontro do mundo do leitor com o mundo da literatura.

Langer (2005) destaca que a construção de representações é influenciada por interações e experiências que se dão dentro e fora da sala de aula. Segundo a autora, tais experiências "nos fornecem uma janela para os pensamentos de nossos alunos, nos convidam a refletir sobre as ideias dos estudantes, a participar e apoiar suas conversas e a fornecer-lhes um espelho no qual possam observar suas ideias em processo de desenvolvimento" (p. 63). Essa participação dos alunos em sala de aula lhes proporciona a oportunidade de explorar suposições, de expor aquilo que pensam, de negociar ideias e de imaginar aquilo que é possível. 
Diante disso, entende-se que as salas de aula devem permitir aos alunos e docentes dar voz às suas próprias ideias, expressar seus pensamentos e compreensões, entender e aceitar o ponto de vista do outro, e perceber a riqueza contida na diversidade. É preciso que "através das diferenças entre as pessoas e as ideias, nós aprendamos não apenas a entender melhor o mundo e como ele funciona, mas também como podemos ser cada vez melhores" (LANGER, 2005, p. 213).

E a literatura assume muito bem esse papel. Ela nos faz pensar melhor, ver melhor as situações que se apresentam, expandir nossa visão, desperta nossa imaginação, nos permite encontrar soluções para muitos problemas e nos leva a perceber uma multiplicidade de sentidos para cada leitura. Mas, acima de tudo, a literatura "ajuda-nos a sermos mais humanos" (LANGER, 2005, p. 213), e é justamente disso que o mundo precisa.

\section{A leitura multimidial}

Quando se fala em literatura, logo nos vem à mente a imagem de livros impressos. Contudo, a leitura pode ser realizada não apenas por meio impresso, mas também por outros suportes de informação, como os meios digitais (computadores, tablets etc.).

A leitura em meio digital faz-nos refletir sobre o espaço que esse suporte vem ocupando na vida contemporânea, nas maneiras de ler e de se comunicar que ele propicia e, ainda, no confronto que vem acontecendo entre esse suporte de leitura e o livro impresso. $\mathrm{O}$ livro, que já foi considerado sinônimo de modernidade, hoje disputa espaço com recursos tecnológicos, que representam o novo e apresentam maior sofisticação. No entanto, é necessário destacar que a preferência pelo uso de recursos tecnológicos não põe em risco a existência do livro.

Zilberman (2007, p. 188), em relação à leitura em suporte digital, destaca que:

Como a introdução à realidade virtual depende do domínio da leitura, essa não sofre ameaça, nem concorrência. Com efeito, fortalece-se, por dispor de mais um mecanismo para sua difusão. Quanto mais se expandir o uso da escrita por intermédio do meio digital, tanto mais a leitura será chamada a contribuir para a consolidação do instrumento, a competência de seus usuários e o aumento de seu público.

Desse modo, diante das telas, os leitores continuam a ler, sendo a leitura ainda mais difundida, mudando apenas o suporte. No entanto, adquirem novos comportamentos, sendolhes permitido, por exemplo, criar seus próprios textos, formando uma tessitura a partir da combinação de vários fragmentos, segundo seus interesses, que vão formando um novo texto. O que esse leitor possui diante de suportes digitais é uma imensa variedade de opções que 
conduzem a uma leitura "globalizada", sendo comum uma leitura não linear, descontínua, favorecida pelas interfaces eletrônicas, já que existe a possibilidade de adentrar outros textos a partir do texto que está sendo lido, formando um imenso hipertexto.

O hipertexto se difere do texto convencional porque não impõe ao leitor uma ordem de leitura, já que diante da tela ele possui vários caminhos a serem seguidos. Porém, deve-se atentar para essa forma de leitura, pois, assim como ela pode permitir uma compreensão global do texto, pode também fragmentá-lo de tal forma que acabe deixando o leitor confuso e disperso.

Segundo Chartier (2007, p. 217):

Não é necessário considerar a tela do computador como uma página, mas como um
espaço tridimensional, dotada de amplitude, de altura e de profundidade, como se os
textos atingissem a superfície da tela a partir do fundo do aparelho.
Consequentemente, no espaço digital não é o objeto que é dobrado, como no caso da
folha do livro manuscrito ou impresso, mas o texto mesmo. A leitura consiste, por
conseguinte, em "desdobrar" esta textualidade móvel e infinita.

Temos, assim, uma nova maneira de ler, uma maneira fragmentada, descontínua, não linear, que permite que o leitor, de dentro de um texto, tenha acesso a outros textos, e, dessa forma, possa "desdobrar" o texto, descobrindo-o, entendendo-o, a partir de uma nova forma de leitura. A relação de interatividade entre leitura e hipertexto permite a ação do leitor sobre o conteúdo, e possibilita um diálogo, mesmo que virtual, com o texto. Portanto, o sentido do texto não está em suas palavras, nem na mente do leitor, mas na interação texto-leitor-contexto, unindo as informações que este já possui com as que o texto fornece para que ele infira significados e represente mentalmente o que o texto provoca ou descreve.

Com relação ao livro eletrônico, Chartier (1999) descreve-o como uma revolução nas estruturas do suporte material do escrito, assim como nas maneiras de ler. Desse modo, esse novo modelo de livro promovido por um suporte virtual transformou as relações sensoriais, elementos importantes no processo de leitura. O que antes era entendido como livro cede espaço para uma nova formatação que constitui o não livro. A tela não possibilita a sensação do manuseio como o livro tradicional. Não há mais uma relação afetiva; os sentidos não são mais os mesmos aguçados como no livro impresso, no qual se fazem presentes e bem marcantes o tato, o contato direto com o objeto, a visão, que é atraída pela cor, pelo formato, e até o olfato, que identifica se o livro tem cheiro de novo, de velho etc. No livro eletrônico, apenas a visão atua extensivamente.

Trata-se, segundo Chartier (2007), de um processo que transcende o livro impresso, seu conteúdo, os conceitos de autoria, a noção de diálogo, alargando o conceito de leitura, 
uma vez que a interatividade é um elemento constante nesse novo formato, que permite o alargamento da noção de leitura e que vai além do livro como conhecemos. No meio eletrônico, há uma diversidade de textos, os quais são produzidos ou recebidos pelos leitores de formas bem semelhantes, normalmente decididas pelo próprio leitor. Dessa forma, cria-se uma continuidade textual que torna difícil distinguir os gêneros de texto, já que a leitura em frente à tela é descontínua. O mundo eletrônico permite uma relação inovadora entre os textos, impondo a estes uma nova forma de organização, que não é mais linear ou dedutiva como era em meio impresso.

As inúmeras formas de interação possibilitadas pelo ambiente virtual entre os cibernautas criam comportamentos inovadores. Atualmente, estamos diante de uma sobrecarga de informação, disponível a todos que têm acesso à Internet. Isso exige que tais informações sejam filtradas pelos leitores, para que possa se transformar em conhecimento, ajustando-se ao contexto em que estamos inseridos.

Em meio a essa nova geração, que tem acesso a tantos novos formatos, não se pode esperar que ajam baseados em comportamentos antigos, sendo necessária, portanto, uma adequação no que se refere às tecnologias e seus usos.

Contudo, é necessário considerar que essa geração não é absoluta, afinal, ainda existem espaços que estão distantes dessa realidade, tanto domicílios como ambientes escolares, que comportam sujeitos que não fazem parte da geração da tecnologia.

Portanto, os novos tempos exigem um repensar das escolas com relação às grades curriculares rígidas e ao ensino ultrapassado. Para isso, é fundamental que estejamos preparados não para a fixação de conteúdos de forma nada interativa, mas para a abertura de canais informatizados de expressão, que possibilitem a construção de aprendizagens, superando os limites espaciais e temporais e aderindo à era da inclusão digital, com escolas que possibilitem o acesso à tecnologia e às variadas formas de ler.

\section{Procedimentos metodológicos da pesquisa}

A abordagem escolhida para esta pesquisa depende não só da reflexão teórica, mas, igualmente, da ação e da reflexão sobre a ação. Em outras palavras, a pesquisa tem como ponto de partida situações concretas, vivenciadas por um grupo e pela própria pesquisadora.

No caso deste estudo, almeja-se perceber em que dimensão a realização de práticas leitoras interferem na formação de leitores, alunos de uma escola rural desprovida de materiais de leitura adequados. Esse procedimento permitiu ampliar as possibilidades de transformação de práticas leitoras e a revitalização da literatura na escola, auxiliando, ainda, 
os professores a verem com mais clareza sua prática em sala de aula, promovendo mudanças atitudinais necessárias para assegurar uma boa formação leitora dos alunos.

Pretende-se, com esta pesquisa, não apenas evidenciar a emancipação do leitor, mas também conscientizá-lo daquilo que tornou possível o alargamento de suas experiências literárias e dos seus horizontes de expectativas.

A pesquisa envolve, também, levantamento bibliográfico e se caracteriza por ser qualitativa, pois a pesquisadora desenvolve conceitos, ideias e entendimentos a partir de padrões encontrados nos dados, ao invés de coletar dados para comprovar teorias, hipóteses e modelos pré-concebidos.

\section{As ações da pesquisa e seus resultados}

A Escola Municipal Ensino Fundamental Francisco Rodrigues dos Santos, escola pública municipal com sede na comunidade de Engenho Grande, na zona rural do município de Água Santa/RS, comporta, atualmente, o total de 29 alunos, todos moradores da comunidade de Engenho Grande e provenientes de famílias que vivem da produção agrícola.

A escola apresenta grande carência de recursos e de materiais de leitura, sendo evidentemente ausente uma estrutura condizente à prática pedagógica com o uso das novas tecnologias. Os alunos possuem como recursos de leitura os livros que estão na biblioteca da escola, que são poucos, e os textos xerografados que os professores utilizam em aula. Além disso, a escola não possui recursos tecnológicos como Datashow ou retroprojetor. Há, no entanto, uma sala de informática bem pequena, composta por quatro computadores e uma impressora multifuncional. Há cerca de seis meses os computadores estão ligados à internet, que é extremamente lenta. Tais máquinas são usadas exclusivamente para as aulas de informática, ministradas uma vez por semana pelo período de trinta minutos por uma professora da área da Pedagogia, que promove dinâmicas em torno de jogos em suas aulas e não permite o acesso dos alunos à internet ${ }^{2}$. $\mathrm{O}$ fato de ter apenas quatro computadores no laboratório obriga os alunos a dividir seu uso, determinando um tempo exíguo de manuseio para cada um, o que dificulta o contato dos sujeitos com o universo virtual.

A biblioteca da escola é uma antiga sala de aula, um espaço pequeno e apertado. A maior parte dos livros da biblioteca é formada por didáticos e uma estante de tamanho considerável os suporta. Em uma estante pequena ficam os livros literários, que são poucos e de publicação não recente, sendo que a maior parte deles está amarelada e exala cheiro

\footnotetext{
${ }^{2}$ Destaca-se que durante a realização das práticas a pesquisadora promoveu o letramento digital dos alunos envolvidos na pesquisa, já que muitos deles têm acesso a computadores apenas na escola durante um curto espaço de tempo.
}

Anu. Lit., Florianópolis, v. 19, n. 1, p. 58-74, 2014. ISSNe 2175-7917 
desagradável, talvez devido ao tempo de existência, talvez devido ao desuso. Outras obras literárias apresentam-se sem capa ou com falta de páginas, e isso, provavelmente, desmotiva os alunos para a leitura. Entretanto, não se pode afirmar que todas as crianças da escola sejam atendidas de forma inadequada pelo sistema de ensino, já que os alunos de $1^{\circ}$ a $5^{\circ}$ ano recebem com frequência livros novos para a biblioteca, o que lhes permite a realização de leituras significativas e motivadoras.

Os alunos da Escola Municipal Ensino Fundamental Francisco Rodrigues dos Santos, participantes desta pesquisa, pertencem ao $8^{\circ}$ e $9^{\circ}$ anos do Ensino Fundamental, sendo que o $8^{\circ}$ ano é composto por seis alunos, cinco meninos e uma menina, e o $9^{\circ}$ ano é formado por três meninos. As duas turmas somam um total de nove alunos.

Os sujeitos participantes da pesquisa são filhos de moradores da comunidade de Engenho Grande, famílias que vivem do trabalho agrícola, com exceção de duas famílias. Observa-se que os alunos não se sentem motivados para a leitura literária, já que dependem quase que exclusivamente dos livros da biblioteca para a realização de suas leituras.

A maioria das famílias possui condições financeiras precárias, sendo que muitas não adquiriram ainda um computador em suas casas pelo fato de acreditarem ser algo dispensável, outras por não terem condições financeiras para a aquisição. Dentre as turmas do ensino fundamental, o $8^{\circ}$ e o $9^{\circ}$ anos são compostos por alunos que, em sua maioria, não têm computador em casa e que, desse modo, não conhecem outras formas de leitura além do material impresso. Quando estão na frente de um computador, mesmo sem acesso à internet, revelam deslumbramento, por ser o único momento em que entram em contato com a tecnologia. É importante mencionar, ainda, que os alunos em questão não têm acesso a livros literários em outros locais da cidade, já que não existe no município biblioteca pública, e a única livraria não possui livros para vender. Assim, fica claro que não há outro local além da escola para a promoção e incentivo à leitura.

Como instrumento para a caracterização dos nove sujeitos envolvidos na pesquisa, foi respondido pelos alunos um questionário com o objetivo de compreender melhor sua realidade como leitores, dando ênfase à leitura literária. O questionário é composto por 25 questões sobre a leitura dos participantes, influências leitoras, preferências, suporte e frequência de leitura, principalmente literária.

Os dados obtidos por meio do questionário evidenciaram a existência de uma baixa frequência e quantidade de leituras, de um local precário de acesso a materiais de leitura e de demonstração de falta de estímulo, de tempo e de desinteresse para ler. Os índices apontaram 
a falta de contato dos sujeitos com computadores, já que 05 não possuem computador em casa, 02 possuem computador sem internet e 02 com internet, destacando-se o desejo deles de estar em contato com a tecnologia. Além disso, os professores foram apontados como os principais influenciadores de leitura, evidenciando-se sua importância como mediadores.

Ficou clara, desse modo, a necessidade de ações que proporcionem o acesso e o trabalho dos alunos envolvidos nesta pesquisa com as tecnologias e com materiais, espaços e leituras diversificados, de acordo com a faixa etária, interesses e necessidades leitoras, de modo que se sintam estimulados para ler por vontade própria, sem a desculpa da exigência escolar.

Foram realizadas, na escola, quatro práticas leitoras com os alunos envolvidos na pesquisa, após a escolha de quatro obras literárias.

A primeira prática leitora foi desenvolvida com a obra Evocação, da autora Marcia Kupstas (2012). O trabalho com essa obra teve o objetivo de proporcionar aos alunos o contato com o mundo do fantástico e do sobrenatural, por meio do relato de histórias que trazem essas características, principalmente pelo fato de ser o gênero de texto que mais atrai os sujeitos desta pesquisa, como foi possível observar por meio do questionário aplicado. Após o trabalho com a obra, os alunos foram estimulados a buscar com familiares ou pessoas conhecidas histórias fantásticas ou sobrenaturais, expondo os resultados ao grupo.

A busca pelas histórias despertou o interesse dos alunos, pois, como se evidenciou por meio da entrevista com os participantes da pesquisa, a literatura fantástica é o tipo de leitura que mais lhes atrai. Desse modo, tanto a leitura da obra Evocação como a busca por histórias fantásticas foram favoráveis à prática leitora, o que permitiu a obtenção de resultados gratificantes. Nesse sentido, Baggio (2011, p. 92) se posiciona, destacando que "a escola que dedica grande esforço para falar de livros, de autores que não vão ao encontro do mundo dos adolescentes, constrói uma barreira prévia com possibilidade de êxito bastante escassa".

Além disso, percebe-se que a mediação leitora foi feita de maneira cativante, provocando o interesse e a curiosidade dos alunos para o tema em discussão, sendo aplicada uma metodologia que despertou nos alunos a vontade de ler. A importância da leitura e de uma boa mediação leitora é levantada por Yunes (2009, p. 58), ao afirmar que:

Dentro e fora da escola, crianças e adultos, precisamos reaprender a ler, a reinventar a leitura. E o começo é perceber que não lemos palavras, lemos sequências nas quais as palavras se comunicam, se negam, se contradizem e nos surpreendem: espreitar suas relações, observar suas ambiguidades pode nos tornar mais perspicazes e sensíveis. Viver a aventura da palavra é viajar pelo tempo/espaço da humana condição. 
Evidenciou-se, por meio da produção textual, que um dos principais resultados obtidos foi a interação dos alunos com a sua própria cultura ou a cultura microrregional que os cerca, por meio de histórias, lendas e conhecimentos culturais de seus conhecidos. Constatou-se a demonstração de interesse por parte dos sujeitos, devido, principalmente, à prática estar relacionada com o contexto real e imediato que os rodeia. Essa prática teve como resultado primordial uma mudança na visão relacionada à literatura, passando a perceber que a produção literária também pode brotar de narrativas contemporâneas e contextualizadas com o mundo que os cerca, o que suscitou o interesse intrínseco dos sujeitos pelo texto literário e um maior envolvimento com a literatura.

A segunda prática leitora foi desenvolvida com a obra $O$ cidadão invisível, de Ivan Jaf (2011), com o objetivo de aproximar os alunos de um assunto que faz parte de suas vidas e que muitos desconhecem o significado, a cidadania, buscando discutir e refletir sobre ações diárias que promovem a cidadania e a boa convivência entre os cidadãos.

Esse exercício de reflexão encontra respaldo nas palavras de Langer (2005, p. 11), as quais asseguram que

por meio da literatura os alunos aprendem a explorar possibilidades e a refletir sobre variadas opções para eles mesmos e para a humanidade. Por meio da literatura, eles encontram a si mesmos, imaginam como as outras pessoas são, valorizam a diferença e buscam justiça; ganham a capacidade de estabelecer analogias e buscam uma melhor compreensão do futuro.

As ideias apontadas pelos alunos diante da leitura dos textos permitiram-lhes refletir sobre a conduta da sociedade em que se inserem, bem como sobre seu próprio comportamento. Petit (2008, p. 78) fala das obras de ficção que nos ajudam a pensar sobre nossa própria existência, afirmando que:

Não é um luxo pensar sobre a própria vida com a ajuda de obras de ficção ou de testemunhos que tocam no mais profundo da experiência humana. De obras que nos ensinam muito sobre nós mesmos, e muito sobre outras vidas [...]. Parece-me inclusive que seja um direito elementar, uma questão de dignidade.

Observou-se que o trabalho com a obra promoveu um grande crescimento nos sujeitos no que concerne à opinião referente às desigualdades sociais que norteiam a sociedade. A prática representou um avanço na leitura crítica, já que privilegiou a abordagem de problemas existentes na sociedade contemporânea, e houve efetivamente uma demonstração, por parte dos sujeitos, de inquietude em relação ao contexto textual apresentado. Por fim, ainda apurou-se uma sensível demonstração de humanismo pelos sujeitos e pela maioria dos entrevistados, verificando-se, dessa forma, a importância de tal 
prática para o ganho de conscientização crítica do mundo que os cerca, proporcionando o desenvolvimento do humanismo dos alunos e não da indiferença, tão presente nos dias atuais em que vários problemas sociais são banalizados devido ao fato de serem tão presentes e comuns na sociedade. Em síntese, o trabalho com a obra permitiu que os alunos se desenvolvessem como leitores, mas, acima de tudo, promoveu mudanças pessoais e seu desenvolvimento como seres humanos críticos, preocupados com o bem-estar social e inconformados com a realidade que se apresenta.

A terceira prática leitora foi desenvolvida com a obra As mais, da autora Patrícia Barboza (2013), com o objetivo de permitir que os alunos se identificassem com as histórias relatadas no livro e pudessem, em conjunto, relembrar e contar suas próprias histórias, vividas por todos os colegas, de modo a engrandecer a amizade existente entre eles.

Constatou-se, por meio da leitura da obra e das discussões, que os alunos puderam se identificar com algumas histórias relatadas no livro, o que tornou a leitura mais prazerosa, já que se aproximava de suas vivências. Petit (2008, p. 38) destaca que:

Ler permite ao leitor, às vezes, decifrar sua própria experiência. É o texto que "lêe" o leitor, de certo modo é ele que o revela; é o texto que sabe muito sobre o leitor, de regiões dele que ele mesmo não saberia nomear. As palavras do texto constituem o leitor, lhe dão um lugar.

Destaca-se, ainda, o desenvolvimento da prática para com o trabalho coletivo, representando um avanço na intercomunicação dos integrantes da turma, ficando demonstrado, para os sujeitos, que da criação literária também pode surgir a interação de conhecimentos, opiniões e lembranças, quebrando o paradigma de que a produção textual somente se dá de forma individual. Ressalta-se que a criação realizada pelos alunos resultou numa criação detalhista e complexa, demonstrando a relevância da utilização de vários pontos de vista no texto elaborado.

Essa experiência de construção textual coletiva promoveu o amadurecimento dos sujeitos para a leitura e o trabalho conjunto, ocasionando, ainda, mudanças no trabalho com o texto pelo contato com distintos suportes de leitura e escrita, proporcionadas, nessa prática leitora, por meio do acesso ao blog "As mais". Destacam-se, com isso, mudanças em seu interesse pela leitura, resultado, inclusive, do trabalho de produção não apenas no papel, mas tendo como suporte também recursos multimidiais.

Em relação às experiências literárias e à construção de sentido proporcionadas pela leitura, Langer (2005, p. 42) destaca que: 
Nas experiências literárias, [...] imaginar torna-se parte essencial na construção de sentido; é a maneira fundamental pela qual os alunos buscam o sentido e chegam à compreensão. $\mathrm{O}$ ato de fazer associações e de explorar está no cerne do conhecimento em literatura, tornando-a uma ferramenta poderosa para pensar acerca das opções disponíveis para cada indivíduo e dos futuros que podem ser imaginados.

A quarta prática leitora foi realizada com a obra Aquela água toda, de João Anzanello Carrascoza (2012). O objetivo do trabalho com a obra foi de que os alunos conhecessem a estrutura do gênero conto e, além disso, tivessem seus sentimentos despertados por meio dos contos do livro, numa ressignificação de suas vidas e experiências.

Nesse sentido, as palavras de Petit (2008, p. 7) merecem destaque, ao afirmar que:

A leitura tem o poder de despertar em nós regiões que estavam até então adormecidas. Tal como o belo príncipe do conto de fadas, o autor inclina-se sobre nós, toca-nos de leve com suas palavras e, de quando em quando, uma lembrança escondida se manifesta, uma sensação ou um sentimento que não saberíamos expressar revela-se com uma nitidez surpreendente.

E os sentimentos são despertados no leitor não apenas enquanto lê, mas posteriormente também, quando terminada a leitura. Nesse momento, segundo Langer (2005), o leitor é capaz de repensar suas interpretações dos sentimentos e ações dos personagens. A autora destaca que "nossas ideias constantemente mudam e se adaptam. Possibilidades diferentes surgem e múltiplas interpretações vêm à mente" (LANGER, 2005, p. 52).

O trabalho com a obra Aquela água toda permitiu que os sentimentos dos alunos fossem despertados durante suas leituras. Além disso, as trocas de experiências durante as discussões e construções de representações acerca dos textos fizeram da leitura uma experiência muito significativa. Nesse sentido, destaca-se que "as trocas de experiências de vida e de leitura tornam o ato de ler uma prática mais rica, dialógica e, por isso, democrática" (RÖHRIG, 2008, p. 18).

Com relação aos sentimentos transmitidos pelas histórias, Petit (2008, p. 39) destaca que:

\footnotetext{
Os escritores nos ajudam a nomear os estados pelos quais passamos, a distingui-los, a acalmá-los, a conhecê-los melhor, a compartilhá-los. Graças a suas histórias, escrevemos a nossa, por entre as linhas. E porque tocam o mais profundo da experiência humana - a perda, o amor, o desespero da separação, a busca de sentido - não há razão para que os escritores não toquem cada um de nós.
}

Os resultados obtidos foram extremamente relevantes tanto à pesquisa quanto aos alunos, que, afastando-se da rotina escolar que normalmente lhes é imposta, tornaram-se mais autônomos e confiantes nas suas capacidades, reunindo alegria, entusiasmo, aprendizagem, novidade e tecnologia no trabalho com textos literários. Silveira $(2010$, p. 122) destaca que é 
possível a formação de leitores multimidiais no ambiente escolar, desde que as atividades sejam bem planejadas e desenvolvidas, tornando a escola "verdadeiramente significativa como fonte de desenvolvimento humanístico". A autora salienta ainda que:

Por meio de iniciativas como substituir aulas tradicionais (com leitura, contestação de perguntas sobre o texto e escrita de outro sobre algum tema evidenciado), que não oferecem desafio algum ao estudante, por aulas no laboratório de informática (vislumbrando a possibilidade de ativar diferentes mídias e fontes), os resultados serão alunos mais competentes, emancipados e interessados nas aulas (SILVEIRA, 2010, p. 122).

Desse modo, entende-se que existem possibilidades de transformação das práticas educativas atuais e que podem ser realizadas ações diferenciadas nas escolas, promovendo um trabalho de leitura significativo e atraente tanto para os alunos como para os professores, com atividades ligadas a um século repleto de tecnologia.

\section{Considerações finais}

O caminho trilhado neste estudo voltou um olhar especial ao enquadramento dos alunos do $8^{\circ}$ e $9^{\circ}$ anos de uma escola rural do município de Água Santa/RS, a E.M.E.F. Francisco Rodrigues dos Santos, por meio do contato dos estudantes com obras literárias diferenciadas e da realização de práticas leitoras multimidiais visando a formação de leitores literários em suportes diferenciados, sempre no intuito de motivá-los para a leitura e de evidenciar a importância do professor como referência na formação e na mediação leitora.

Acrescenta-se nessa caminhada conclusiva a importância da leitura, em especial a literária, como uma atividade que contribui para a conquista da cidadania e da liberdade individual. A escola e os espaços de leitura, como a biblioteca, contribuem para o processo de formação do leitor, sendo que o ambiente escolar ainda é um espaço privilegiado de leitura e o professor ainda é um referencial para os jovens e para a família, atuando como um dos principais mediadores entre a leitura e o livro, seja impresso ou digital.

Constatou-se, por meio da realização das práticas leitoras, que os sujeitos foram envolvidos não apenas em um mundo de obras, mas no vasto universo da cultura literária, o que promoveu seu amadurecimento e seu desenvolvimento não apenas como leitores, mas também como seres humanos.

Observou-se que o processo desenvolvido neste estudo teve papel decisivo, inclusive, na formação daqueles leitores menos estimulados, os quais passaram a ver a leitura com outros olhos, com olhos de encantamento. Tal aspecto pôde ser percebido durante os debates sobre as obras, onde os sujeitos que se sentiam desestimulados participaram 
ativamente, expondo suas experiências leitoras e seus pontos de vista. Além disso, o estímulo conquistado ficou evidenciado por meio das produções textuais, já que todos os alunos, sem exceção, demonstraram grande contentamento e interesse ao realizá-las.

Entretanto, dentre todas as atividades realizadas, as que mais envolveram os alunos foram aquelas realizadas na sala de informática. Assim, observa-se que a tecnologia, integrada ao processo de formação de leitores, permitiu o andamento de um projeto de sensibilização artística e de aprofundamento interior nos sujeitos.

Ficou claro que os alunos sentem a necessidade de um contato maior com os meios multimidiais, seja para atividades de leitura ou de produção escrita. Acredita-se que a possibilidade do contato com leituras em suporte digital aproximou os alunos dos livros, fazendo com que a leitura acontecesse efetivamente. Weschenfelder, Rettenmaier e Rösing (2003, p. 63), em relação à leitura na era da cibercultura, destacam: “As concepções tradicionais de leitura pouco representam em uma atualidade de constante evolução tecnológica". Desse modo, a pesquisa faz refletir que a internet, por ter em si fontes de leitura, é necessária tanto para professores como para alunos, constituindo-se como ferramenta indispensável em escolas preocupadas com a promoção de leituras de múltiplas linguagens. A tecnologia digital, quando aliada a práticas de leitura e escrita bem formuladas e aplicadas, pode conduzir ao conhecimento, ao saber e à realização de uma leitura prazerosa e motivadora.

Concluiu-se, nessa perspectiva, que as experiências leitoras proporcionadas pelas práticas desenvolvidas exerceram um papel singular no que concerne à apropriação da leitura, obtendo-se resultados extremamente positivos na formação de leitores e no trabalho de mediação de leitura. Contudo, as experiências leitoras oportunizadas por meio das práticas exigem continuidade, a fim de que não se percam os leitores conquistados.

\section{Referências}

BAGGIO, Ana Cristina. Em busca de leitores no contexto da escola. 2011. Dissertação (Mestrado em Letras) - Programa de Pós-Graduação em Letras, Universidade de Passo Fundo, Passo Fundo, 2011.

BARBOZA, Patrícia. As mais. 1 ed. Campinas-SP: Verus, 2013.

CARRASCOZA, João Anzanello. Aquela água toda. São Paulo: Cosac Naify, 2012.

CHARTIER, Roger. A escrita na tela: ordem do discurso, ordem dos livros e maneiras de ler. In: RETTENMAIER, Miguel; RÖSING, Tania M. K. (Orgs.). Questões de leitura no hipertexto. Passo Fundo: Ed. Universidade de Passo Fundo, 2007, p. 200-222. 
A Aventura do Livro: do leitor ao navegador. Trad. de Reginaldo de Moraes. São Paulo: Editora UNESP/ Imprensa Oficial do Estado, 1999.

JAF, Ivan. O cidadão invisível. 1 ed. São Paulo: Ática, 2011.

KUPSTAS, Marcia. Evocação. 1 ed. São Paulo: Ática, 2012.

LANGER, Judith A.. Pensamento e experiência literários: compreendendo o ensino de literatura. Tradução: Luciana Lhullier da Rosa, Maria Lúcia Bandeira Vargas. Passo Fundo: Ed. Universidade de Passo Fundo, 2005.

PETIT, Michèle. Os jovens e a leitura: uma nova perspectiva. Trad. de Celina Olga de Souza. São Paulo: Ed. 34, 2008.

RÖHRIG, Adriana. O papel das Jornadinhas Nacionais de Literatura na formação do leitor. 2008. Dissertação (Mestrado em Letras) - Programa de Pós-Graduação em Letras, Universidade de Passo Fundo, Passo Fundo, 2008.

SILVEIRA, Mariane Rocha. Blog: eu te lendo e eu te escrevendo. 2010. Dissertação (Mestrado em Letras) - Programa de Pós-Graduação em Letras, Universidade de Passo Fundo, Passo Fundo, 2010.

WESCHENFELDER; RETTENMAIER; RÖSING. Práticas leitoras para uma cibercivilização: vivências interdisciplinares e multimidiais de leitura. Passo Fundo: UPF, 2003.

YUNES, Eliana. Tecendo um leitor: uma rede de fios cruzados. Curitiba: Ayamará, 2009.

ZILBERMAN, Regina. A leitura no mundo digital. In: RETTENMAIER, Miguel; RÖSING, Tania M. K. (Orgs.). Questões de leitura no hipertexto. Passo Fundo: Ed. Universidade de Passo Fundo, 2007, p. 178-199.

[Recebido em fevereiro de 2014 e aceito para publicação em abril de 2014]

\section{Reading and technology: graduate readers in a rural school}

Abstract: This study, of empirical social research, consists of an analysis of the development dimension reading practices on the reader formation of the students which are in the 8th and 9th grade of Escola Municipal de Ensino Fundamental Francisco Rodrigues dos Santos, a rural school in the city of Água Santa/RS, with emphasis on representations built by students. The two groups together have nine students, but only four of them have a computer at home and only one has internet access. In addition, the school, even with access to the internet, does not allow students to enjoy it. For this study, a bibliographic research based on Judith Langer's theoretical assumptions was developed about the construction of representations and of Michèle Petit and after, an action research which involved, initially, the application of a questionnaire to students with issues related to reading. Based on the answers, it was possible to draw a profile of the participants of this study. Then, literaly books were distributed to students, according to his literary tastes and, after reading, were developed four reading practices at school involving reading and writing. This action allowed the contact of the surveyed students with innovative and differentiated readings, opening ways for the formation of literary readers including digital support, always in order to motivate them to read and 
highlight the importance of the teacher as a reference in training and in mediation reader. The work dedicated a depht look at actions of Pré-Jornadinha, in a process of reflection on the reading as a social and literary practice associated with the artistic and cultural manifestations in different media.

Keywords: Forming the reader. Reading. Reading mediation. Technology.

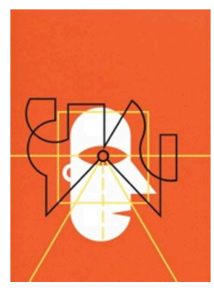

